Article

\title{
Dimensionality Variation in Dinuclear Cu(II) Complexes of a Heterotritopic Pyrazolate Ligand
}

\author{
Chris S. Hawes ${ }^{1,2, *}$ and Paul E. Kruger ${ }^{1, *}$
}

1 MacDiarmid Institute for Advanced Materials and Nanotechnology, Department of Chemistry, University of Canterbury, Private Bag 4800, Christchurch 8140, New Zealand

2 School of Chemistry, Monash University, Clayton, VIC 3800, Australia

* Authors to whom correspondence should be addressed; E-Mails: chris.hawes@ monash.edu (C.S.H.); paul.kruger@canterbury.ac.nz (P.E.K.); Tel.: +64-3-364-2438 (P.E.K.);

Fax: +64-3-364-2110 (P.E.K.).

Received: 21 January 2014; in revised form: 6 February 2014 / Accepted: 10 February 2014 / Published: 26 February 2014

\begin{abstract}
Two new $\mathrm{Cu}$ (II) complexes of the ligand 3-carboxy-5-(2-pyridyl)- $1 H$-pyrazole, $\mathbf{H}_{2} \mathbf{L} \mathbf{1}$, have been prepared and structurally characterized and found to be comprised of a similar $\left[\mathbf{M}_{2} \mathbf{L}_{2}\right]$ dimer motif. Subtle variation in the synthetic conditions allowed isolation of two metal complexes: $\left[\mathrm{Cu}_{2} \mathbf{L 1}_{2}(\mathrm{MeOH})_{2}\right]$, 1, a discrete dimer linked by hydrogen bonding interactions in the solid state, and poly- $\left[\mathrm{Cu}_{2} \mathbf{L} \mathbf{1}_{2}\right], \mathbf{2}$, a polymeric material where the dimer motif is linked by carboxylate bridges to give an extended two-dimensional sheet. The selective isolation of each phase by careful synthetic control highlights the subtlety and importance of the underlying synthetic conditions.
\end{abstract}

Keywords: heterocycles; crystallography; metallosupramolecular chemistry; crystal engineering

\section{Introduction}

Coordination architectures containing nitrogen heterocyclic ligands have a rich history, and continue to attract active research within the coordination and supramolecular chemistry communities [1-3]. The ubiquity of heterocyclic species in biochemistry, especially as therapeutic agents, has led to extensive knowledge being attained with regard to the synthesis and properties of a wide range of heterocyclic species [4-6]. Such compounds are highly relevant to the field of metallosupramolecular chemistry, where novel ligand classes are required to extend the fundamental 
understanding of the science towards achieving specific application [7,8]. Many instances of the utility of nitrogen heterocycles in metallosupramolecular assemblies have recently been reported; for example, the favourable binding strength of diazoles and diazolates has been utilized to prepare extremely robust metal-organic frameworks [9-12], while the ready functionalization of heterocyclic species has given rise to many examples of rationally designed discrete architectures [13-18]. The use of nitrogen heterocyclic ligands also provides opportunities for the introduction of magnetic, catalytic or gas sorption properties into supramolecular systems [19-21].

Pyrazole containing ligands, although not as ubiquitous as pyridine or imidazole based ligands, have become an increasingly popular choice of coordinating entity in the synthesis of metallo-supramolecular assemblies [22-24]. Substitution at the 3- and/or 5-positions of the pyrazole ring gives rise to a series of compounds capable of chelating two adjacent metal ions, to form discrete clusters or polymeric architectures, such as the well-studied 3,5-dicarboxy- $1 H$-pyrazole and 3,5-di(2-pyridyl)- $1 H$-pyrazole ligands $[25,26]$. Despite the popularity of symmetric 3,5-disubstituted pyrazole ligands, there are few examples of unsymmetrical 3,5-disubstituted pyrazole ligands. Herein we report the first two structurally characterized complexes of 3-carboxy-5-(2-pyridyl)-1H-pyrazole, $\mathbf{H}_{2} \mathbf{L} \mathbf{1}$ (Figure 1).

Figure 1. Structure of $\mathbf{H}_{2} \mathbf{L 1}$.

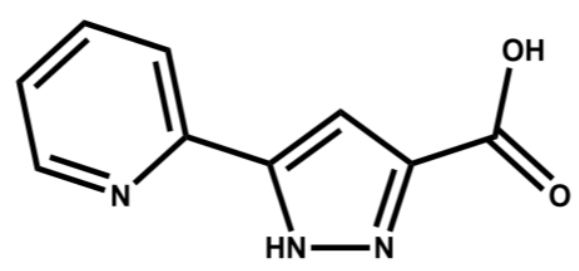

$\mathrm{H}_{2} \mathrm{~L} 1$

\section{Results and Discussion}

\subsection{Synthesis of $\left[\mathrm{Cu}_{2} \mathrm{LI}_{2}(\mathrm{MeOH})_{2}\right], \mathbf{I}$}

Compound $\mathrm{H}_{2} \mathrm{L1}$ was combined with an excess of $\mathrm{CuCl}_{2} \cdot 2 \mathrm{H}_{2} \mathrm{O}$ in $5 \mathrm{~mL}$ of methanol and heated to $130{ }^{\circ} \mathrm{C}$ in a sealed vessel, allowed to dwell for $24 \mathrm{~h}$, and cooled to room temperature at $5{ }^{\circ} \mathrm{C} / \mathrm{h}$. The purple rod crystals obtained in $21 \%$ yield were subjected to single crystal X-ray diffraction, whereupon the data were solved and the structure model refined in the triclinic space group $P \overline{1}$ (R-factor $3.38 \%$ ). The structure was found to consist of two equivalent $\mathrm{Cu}$ (II) ions coordinated by two doubly deprotonated ligand molecules, forming a neutral centrosymmetric $\left[\mathrm{Cu}_{2}(\mathbf{L 1})_{2}\right]$ species. The axial coordination sites of the copper ions are occupied by methanol molecules on opposing faces of the dimer, leading to square pyramidal coordination geometry. The two $\mathrm{Cu}$ (II) ions are separated by a distance of 3.9583(6) $\AA$. The bite angles subtended by the two chelating domains, $79.94(8)^{\circ}$ and $80.48(7)^{\circ}$ for $\mathrm{N}(2)-\mathrm{Cu}(1)-\mathrm{N}(9)$ and $\mathrm{N}(10)-\mathrm{Cu}(1)-\mathrm{O}(14)$, respectively, impart a relatively regular coordination geometry, while the angles from the coordinating methanol oxygen atom to each atom in the basal plane via the $\mathrm{Cu}$ (II) centre all lie in the range $90.03(7)^{\circ}-96.76(8)^{\circ}$. The pyridine-pyrazole system was found to be effectively coplanar, with an interplanar angle of $0.60(9)^{\circ}$, while the torsion 
angle of the pyrazole-carboxylate system of $0.7(3)^{\circ}$ is also planar. The $\mathrm{Cu}$ (II) ions were found to lie within the ligand mean plane within crystallographic error. The structure of complex $\mathbf{1}$ is shown in Figure 2.

Figure 2. Structure of 1 with partial atom labelling scheme. Hydrogen atoms are omitted for clarity.

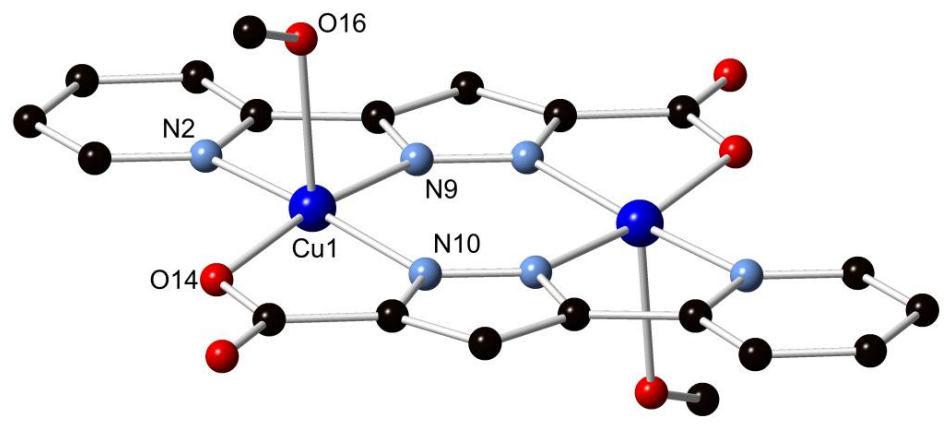

Molecules of $\mathbf{1}$ interact by way of hydrogen bonding between the methanol ligands and coordinating carboxylate oxygen atoms of the adjacent complexes. Each pair of dimers is held together by two such interactions. The hydrogen bonded chain is further supported by a strong offset face-to-face $\pi-\pi$ interaction with mean interplanar distance 3.285(2) $\AA$, in which the metal ions themselves are separated by a distance of 3.7711(7) A. Propagation of these interactions leads to the formation of a one-dimensional polymeric structure running parallel to the $a$ unit cell axis (Figure 3). The crystals remain stable on drying in air, and thermogravimetric analysis showed good thermal stability below $75^{\circ} \mathrm{C}$, whereafter a rapid one-step loss of mass occurs, consistent with complete removal of the coordinated methanol molecules. After desolvation the remaining material loses no further mass until decomposition above $300{ }^{\circ} \mathrm{C}$. On heating in air, a loss of single crystallinity was observed in conjunction with the loss of the coordinating methanol molecules.

Figure 3. Extended structure of 1 showing the one-dimensional hydrogen-bonded chain formed between the coordinating methanol molecules and the non-coordinating carboxylate oxygen atoms. Hydrogen atoms not taking part in hydrogen bonding omitted for clarity.

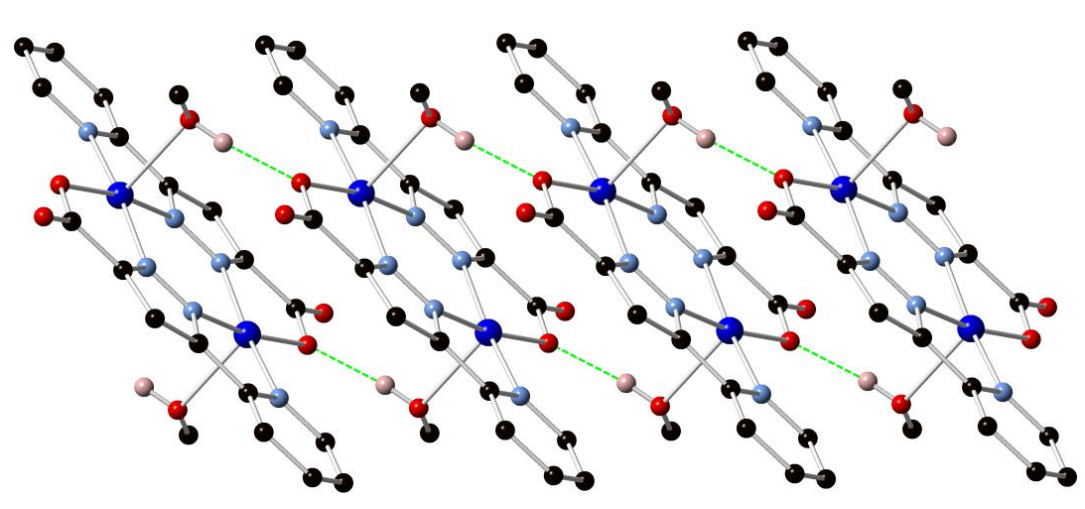

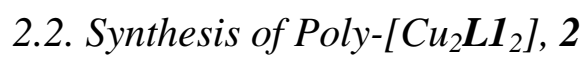

In a similar method to that used for the synthesis of complex $\mathbf{1}$, complex $\mathbf{2}$ was prepared by the solvothermal reaction of $\mathbf{H}_{2} \mathbf{L 1}$ with a slight excess of $\mathrm{Cu}\left(\mathrm{NO}_{3}\right)_{2} \cdot 3 \mathrm{H}_{2} \mathrm{O}$ in $5 \mathrm{~mL}$ of methanol, 
employing the same heating cycle described above. The dark-blue block crystals obtained in $62 \%$ yield were analysed by single crystal X-ray diffraction, revealing a structure in the monoclinic space group $P 2_{1} / c$ (R-factor $2.96 \%$ ). The structure was found to consist of an equivalent $\left[\mathrm{Cu}_{2}(\mathbf{L 1})_{2}\right]$ dimer motif to that seen in 1 (Figure 4); however, instead of methanol molecules coordinating in the axial sites, the non-chelating carboxylate oxygen atoms of adjacent complexes act as donor atoms, forming a polymeric assembly. The axial $\mathrm{Cu}(1)-\mathrm{O}(14)$ distance of 2.278(2) $\AA$ is shorter than the axial bond in 1 of 2.341(2) $\AA$. The remaining structural parameters for the dimer itself are closely related to those found in 1 , although the $\mathrm{Cu}$ (II) ions lie out of the $\mathrm{N}_{3} \mathrm{O}$ basal plane by $0.155(1) \AA$ towards the axial carboxylate oxygen atoms in $\mathbf{2}$, leading to a longer $\mathrm{Cu}-\mathrm{Cu}$ distance of 3.9790(9) $\AA$. The pyridine-pyrazole interplanar angle of $5.78(9)^{\circ}$ is notably larger than that observed in $\mathbf{1}$, as is the carboxylate-pyrazole torsion of $3.8(3)^{\circ}$, suggesting a conformational change is required to adopt this new binding mode.

Figure 4. (a) Structure of 2 with partial atom labelling scheme; (b) the polymer formed by bridging carboxylate linkages between adjacent dimers. Hydrogen atoms are omitted for clarity. Symmetry codes used to generate equivalent atoms: $i+x, 1 / 2-y,-1 / 2+z$.

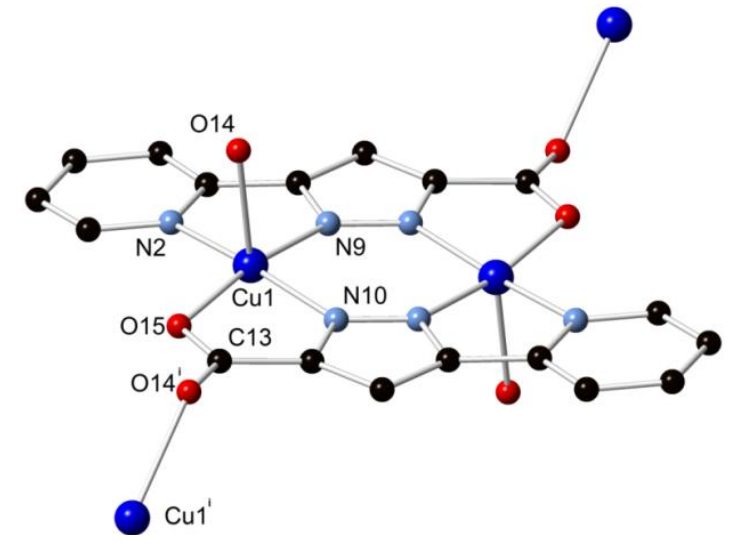

(a)

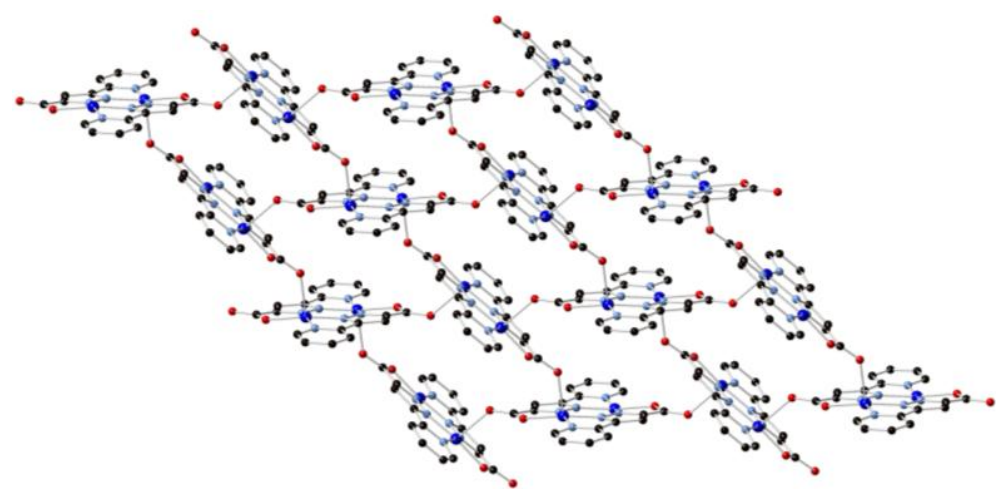

(b)

The polymer formed by linking adjacent $\left[\mathrm{Cu}_{2}(\mathbf{L 1})_{2}\right]$ dimer motifs through bridging carboxylate oxygen atoms is a $(4,4) 2$-dimensional sheet that lies parallel to the crystallographic $b c$ plane, Figure 4.

The network displays a herringbone-type pattern featuring a $\mathrm{C}(13)-\mathrm{O}(14)-\mathrm{Cu}(1)$ angle of $133.51(15)^{\circ}$ which imparts an interplanar angle of $42.17(7)^{\circ}$ between the mean planes of adjacent dimers (Figure 5). The windows of each circuit are interdigitated by two adjacent sheets featuring strong offset face-to-face $\pi-\pi$ stacking arrangements with mean interplanar distances of 3.235(2) $\AA$ and 3.272(2) $\AA$ for the two types of interaction. Unlike those found in 1, however, these interactions do not bring adjacent $\mathrm{Cu}$ (II) centres into close proximity. While elemental analysis suggested some association of atmospheric water molecules upon prolonged standing in air, thermal analysis of a freshly isolated sample of 2 showed no significant mass loss below $300{ }^{\circ} \mathrm{C}$, whereupon single step decomposition occurs. 
Figure 5. Representation of the packing of adjacent polymeric sheets in 2. Independent networks are coloured separately. Hydrogen atoms are omitted for clarity.
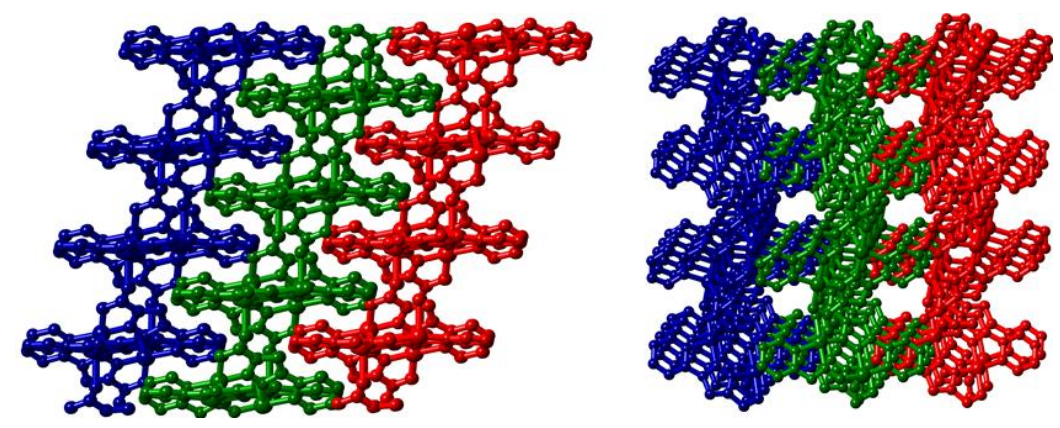

\subsection{Discussion}

Comparison of the structures of $\mathbf{1}$ and $\mathbf{2}$ reveal obvious similarities and differences. While the intramolecular structural features of the two dimer motifs are very similar, save for slight distortions caused by stronger axial coordination in $\mathbf{2}$, the extended structures are markedly different, due to the variation in the nature of the axial ligand. As might be expected, the polymeric compound 2 was isolated in considerably higher yield than $\mathbf{1}$ under similar synthetic conditions. This is most likely due to solubility effects, where the insoluble polymeric species 2 would be expected to precipitate upon formation, while the discrete species $\mathbf{1}$ is soluble in the supernatant solution.

It was observed that alteration to the synthetic conditions of $\mathbf{1}$ and $\mathbf{2}$, such as lowering the dwell temperature (even by as little as $10^{\circ} \mathrm{C}$ ), increasing the dwell time, or altering the solution concentrations and stoichiometries typically yielded mixed phases of $\mathbf{1}$ and $\mathbf{2}$, often in the presence of amorphous materials. Indeed, even the choice of anion used in the synthesis displayed an effect on the outcome of the reaction, similarly leading to mixed or amorphous phases of $\mathbf{1}$ and $\mathbf{2}$ when the syntheses were attempted using copper chloride or nitrate in different stoichiometric ratios, and when experimenting with additional anions. We noted that a pure phase of $\mathbf{1}$ was only achieved when using copper chloride as a starting material, while $\mathbf{2}$ could only be prepared as a pure phase when using copper nitrate, however mixed phases of $\mathbf{1}$ and $\mathbf{2}$ were available from both precursors at different stoichiometries. Especially given the lack of chloride or nitrate anions present in the structures of $\mathbf{1}$ and $\mathbf{2}$, the observation of an anion dependence on the resulting crystalline phase is interesting, and may potentially be explained by a kinetic influence based on the stability of the soluble $\mathrm{Cu}$ (anion) complex in the non-aqueous reaction medium. Only through careful screening of synthetic conditions were pure phases of $\mathbf{1}$ and $\mathbf{2}$ isolated (confirmed by X-ray powder diffraction, supporting information). These observations are in keeping with the known tendency for extremely subtle changes to synthetic conditions to cause dramatic variation in the outcome of supramolecular syntheses [15], and emphasises the delicate balance of competing effects which give rise to crystallisation of metal-organic species from reaction mixtures.

\section{Experimental Section}

\subsection{General Considerations}

Compound $\mathbf{H}_{2} \mathbf{L 1}$ was prepared using reported methods [27]. All reagents and solvents were purchased from standard suppliers and used as received. Melting points were recorded on an 
Electrothermal melting point apparatus in air, and are uncorrected. Thermogravimetric analysis (Supporting Information) was carried out using a TA instruments Q600 SDT Thermogravimetric Analysis instrument (TA instruments, New Castle, PA, USA), with samples heated on alumina crucibles under nitrogen flow of $100 \mathrm{~mL} / \mathrm{min}$. Infrared spectroscopy was performed using a PerkinElmer Spectrum One Fourier Transform Infrared instrument (PerkinElmer, Waltham, MA, USA) operating in diffuse reflectance mode. Elemental analysis was carried out by Campbell Microanalytical Laboratory, University of Otago, Dunedin, New Zealand. X-ray powder diffraction (Supporting Information) was carried out using an Agilent SuperNova instrument (Agilent, Santa Clara, CA, USA) using $\mathrm{Cu} \mathrm{K \alpha}$ radiation $(\lambda=1.5406 \AA)$. Samples were ground with a small quantity of immersion oil and mounted on a glass fibre, and $\Phi$ scans were carried out with 150 s exposure time. Diffraction data were then radially integrated to generate plots of intensity versus $2 \theta$ angle.

\subsection{X-Ray Crystallography}

Refinement data are presented in Table 1.

Table 1. Crystallographic and refinement parameters for compounds $\mathbf{1}$ and $\mathbf{2 .}$

\begin{tabular}{|c|c|c|}
\hline Compound & 1 & 2 \\
\hline Empirical formula & $\mathrm{C}_{20} \mathrm{H}_{18} \mathrm{Cu}_{2} \mathrm{~N}_{6} \mathrm{O}_{6}$ & $\mathrm{C}_{18} \mathrm{H}_{10} \mathrm{Cu}_{2} \mathrm{~N}_{6} \mathrm{O}_{4}$ \\
\hline Formula weight & 565.48 & 501.40 \\
\hline Temperature/K & $113(2)$ & $113(2)$ \\
\hline Crystal system & Triclinic & Monoclinic \\
\hline Space group & $P \overline{1}$ & $P 2_{1} / c$ \\
\hline $\mathrm{a} / \AA ̊ \AA$ & $5.0428(3)$ & $7.9539(4)$ \\
\hline $\mathrm{b} / \AA$ & $9.7974(5)$ & $13.8622(7)$ \\
\hline $\mathrm{c} / \AA$ & $10.9673(6)$ & $7.4109(4)$ \\
\hline$\alpha /{ }^{\circ}$ & $111.019(3)$ & 90.00 \\
\hline$\beta /{ }^{\circ}$ & $90.989(4)$ & $93.976(3)$ \\
\hline$\gamma /{ }^{\circ}$ & $93.939(4)$ & 90.00 \\
\hline Volume $/ \AA^{3}$ & $504.09(5)$ & $815.15(7)$ \\
\hline $\mathrm{Z}$ & 1 & 2 \\
\hline$\rho_{\text {calc }} \mathrm{mg} / \mathrm{mm}^{3}$ & 1.863 & 2.043 \\
\hline $\mathrm{m} / \mathrm{mm}^{-1}$ & 2.165 & 2.655 \\
\hline $\mathrm{F}(000)$ & 286.0 & 500.0 \\
\hline Crystal size $/ \mathrm{mm}^{3}$ & $0.6 \times 0.13 \times 0.09$ & $0.24 \times 0.13 \times 0.09$ \\
\hline Radiation & Mo $\mathrm{K} \alpha(\lambda=0.71073)$ & Mo $\mathrm{K} \alpha(\lambda=0.71073)$ \\
\hline $2 \theta$ range for data collection & $6.98^{\circ}$ to $59^{\circ}$ & $5.14^{\circ}$ to $58.98^{\circ}$ \\
\hline Index ranges & $-6 \leq h \leq 6,-13 \leq k \leq 13,-15 \leq l \leq 15$ & $-11 \leq h \leq 11,-19 \leq k \leq 19,-10 \leq l \leq 10$ \\
\hline Reflections collected & 10778 & 20313 \\
\hline Independent reflections & $2764\left[\mathrm{R}_{\mathrm{int}}=0.0471, \mathrm{R}_{\sigma}=0.0493\right]$ & $2270\left[\mathrm{R}_{\mathrm{int}}=0.0626, \mathrm{R}_{\sigma}=0.0371\right]$ \\
\hline Data/restraints/parameters & $2764 / 2 / 158$ & $2270 / 0 / 136$ \\
\hline Goodness-of-fit on $\mathrm{F}^{2}$ & 1.054 & 1.052 \\
\hline Final $R$ indexes $[I>=2 \sigma(I)]$ & $\mathrm{R}_{1}=0.0338, \mathrm{wR}_{2}=0.0674$ & $\mathrm{R}_{1}=0.0294, \mathrm{wR}_{2}=0.0665$ \\
\hline Final $\mathrm{R}$ indexes [all data] & $\mathrm{R}_{1}=0.0500, \mathrm{wR}_{2}=0.0722$ & $\mathrm{R}_{1}=0.0432, \mathrm{wR}_{2}=0.0715$ \\
\hline Largest peak/hole/e $\AA^{-3}$ & $0.47 /-0.52$ & $0.47 /-0.48$ \\
\hline
\end{tabular}


X-ray crystallographic data collection was carried out with a Bruker APEX-II instrument (Bruker AXS, Madison, NY, USA) using graphite-monochromated Mo $\mathrm{K} \alpha(\lambda=0.71073 \AA)$ radiation. All structures were solved using direct methods with SHELXS [28] and refined on $\mathrm{F}^{2}$ using all data by full matrix least-squares procedures with SHELXL-97 [29] within OLEX-2 [30]. Non-hydrogen atoms were refined with anisotropic displacement parameters. Hydrogen atoms were included in calculated positions, or were manually assigned from residual electron density where appropriate, with isotropic displacement parameters 1.2 times the isotropic equivalent of their carrier atoms. The functions minimized were $\Sigma \mathrm{w}\left(\mathrm{F}_{\mathrm{o}}^{2}-\mathrm{F}_{\mathrm{c}}^{2}\right)$, with $\mathrm{w}=\left[\sigma^{2}\left(\mathrm{~F}_{\mathrm{o}}^{2}\right)+\mathrm{aP} 2+\mathrm{bP}\right]^{-1}$, where $\mathrm{P}=\left[\max \left(\mathrm{F}_{\mathrm{o}}\right)^{2}+2 \mathrm{~F}_{\mathrm{c}}^{2}\right] / 3$. Crystallographic data available in CIF format from the Cambridge Crystallographic Data Centre; CCDC 982471-982472.

\subsection{Synthesis of 1}

To $\mathbf{H}_{2} \mathbf{L 1}(10 \mathrm{mg}$; $53 \mu \mathrm{mol})$ in $5 \mathrm{~mL}$ of $\mathrm{MeOH}$ was added $\mathrm{CuCl}_{2} \cdot 2 \mathrm{H}_{2} \mathrm{O}(20 \mathrm{mg} ; 120 \mathrm{mmol})$, and the mixture was heated in a $23 \mathrm{~mL}$ acid digestion bomb to $100{ }^{\circ} \mathrm{C}$, allowed to dwell for $24 \mathrm{~h}$, and cooled to room temperature at $4{ }^{\circ} \mathrm{C} / \mathrm{h}$. The purple rod crystals were isolated by filtration, washed with methanol and air dried. Yield $6.2 \mathrm{mg}(21 \%)$; m.p. > $300{ }^{\circ} \mathrm{C}$; (Found C, 42.8; H, 3.37; N, 14.9; $\mathrm{C}_{10} \mathrm{H}_{9} \mathrm{~N}_{3} \mathrm{O}_{3} \mathrm{Cu}$ requires $\mathrm{C}, 42.5 ; \mathrm{H}, 3.21 ; \mathrm{N}, 14.9 \%) ; v_{\max }(\mathrm{KBr}) / \mathrm{cm}^{-1} 2821 \mathrm{~s} \mathrm{br,} 1663 \mathrm{~m}, 1519 \mathrm{w}, 1451 \mathrm{~s}, 1317 \mathrm{~m}$, $1254 \mathrm{~m}, 1028 \mathrm{~m}, 986 \mathrm{~m}, 780 \mathrm{~s}$.

\subsection{Synthesis of 2}

To $\mathbf{H}_{2} \mathbf{L 1}(10 \mathrm{mg} ; 53 \mu \mathrm{mol})$ in $5 \mathrm{~mL} \mathrm{MeOH}$ was added $\mathrm{CuNO}_{3} \cdot 3 \mathrm{H}_{2} \mathrm{O}(15 \mathrm{mg} ; 60 \mathrm{mmol})$, and the mixture was heated in a $23 \mathrm{~mL}$ acid digestion bomb to $130{ }^{\circ} \mathrm{C}$, allowed to dwell for $24 \mathrm{~h}$, and cooled to room temperature at $5{ }^{\circ} \mathrm{C} / \mathrm{h}$. The blue block crystals of the product were isolated by filtration and air dried. Yield $8.3 \mathrm{mg}\left(62 \%\right.$ ). m.p. > $300{ }^{\circ} \mathrm{C}$; (Found C, 42.3; H, 2.10; N, 16.3; $\mathrm{C}_{18} \mathrm{H}_{10} \mathrm{~N}_{6} \mathrm{O}_{4} \mathrm{Cu}_{2} \cdot 0.5 \mathrm{H}_{2} \mathrm{O}$ requires $\mathrm{C}, 42.4 ; \mathrm{H}, 2.17 ; \mathrm{N}, 16.5 \%) ; v_{\max }(\mathrm{KBr}) / \mathrm{cm}^{-1} 3061 \mathrm{~m}, 2331 \mathrm{~m}, 1609 \mathrm{~s}, 1583 \mathrm{~m}, 1518 \mathrm{~m}, 1446 \mathrm{~m}$, 1286 s, 1075 m, 1045 m, 1021 w, 992 m, 814 m, 797 m, 777 s, 647 w.

\section{Conclusions}

We have prepared and characterised two dinuclear $\mathrm{Cu}(\mathrm{II})$ complexes from the hetero-tritopic compound 3-carboxy-5-(2-pyridyl)-1H-pyrazole $\mathbf{H}_{2} \mathbf{L} \mathbf{1}$. Complex $\mathbf{1}$ exists as a discrete $\left[\mathbf{M}_{\mathbf{2}} \mathbf{L}_{2}\right]$ dimer, which associates in the solid state by way of hydrogen bonding between axially coordinated methanol molecules and carboxylate oxygen atoms from adjacent molecules. By slightly modifying the synthetic conditions, we obtained a related complex, 2 , where similar $\left[\mathbf{M}_{2} \mathbf{L}_{2}\right]$ units are connected by carboxylate bridges to form a 2-dimensional coordination polymer. Adjacent polymeric sheets of $\mathbf{2}$ associate by interdigitation, supported by $\pi-\pi$ interactions, giving a densely packed network. The preparation of the two closely related complexes by subtle variation in synthesis conditions underpins the delicate balance of effects governing the formation of crystalline metallosupramolecular assemblies. 


\section{Acknowledgments}

The authors wish to acknowledge the University of Canterbury College of Science (Ph.D. Scholarship for Chris Hawes) and the Marsden Fund for financial support.

\section{Conflicts of Interest}

The authors declare no conflict of interest.

\section{References}

1. Tomasik, P.; Ratajewicz, Z. Chemistry of Heterocyclic Compounds. In Pyridine-Metal Complexes; Newkome, G.R., Strekowski, L., Eds.; John Wiley \& Sons: New York, NY, USA, 1985.

2. Steel, P.J. Ligand design in multimetallic architectures: Six lessons learned. Acc. Chem. Res. 2005, 38, 243-250.

3. Bai, S.-Q.; Young, D.J.; Hor, T.S. Nitrogen-rich azoles as ligand spacers in coordination polymers. Chem. Asian J. 2011, 6, 292-304.

4. Eicher, T.; Hauptmann, S.; Speicher, A. The Chemistry of Heterocycles; Wiley-VCH: Weinheim, Germany, 2003.

5. De Luca, L. Naturally occurring and synthetic imidazoles: Their chemistry and their biological activities. Curr. Med. Chem. 2013, 13, 1-23.

6. Joule, J.A.; Mills, K. Heterocycles in Medicine. In Heterocyclic Chemistry at a Glance; John Wiley \& Sons, Ltd.: Chichester, UK, 2012.

7. Hawes, C.S.; Babarao, R.; Hill, M.R.; White, K.F.; Abrahams, B.F.; Kruger, P.E. Hysteretic carbon dioxide sorption in a novel copper(II)-indazole-carboxylate porous coordination polymer. Chem. Commun. 2012, 48, 11558-11560.

8. An, J.; Farha, O.K.; Hupp, J.T.; Pohl, E.; Yeh, J.I.; Rosi, N.L. Metal-adeninate vertices for the construction of an exceptionally porous metal-organic framework. Nat. Commun. 2012, 3 , doi:10.1038/ncomms1618.

9. Choi, H.J.; Dinca, M.; Long, J.R. Broadly hysteretic $\mathrm{H}_{2}$ adsorption in the microporous metal-organic framework $\mathrm{Co}$ (1,4-benzenedipyrazolate). J. Am. Chem. Soc. 2008, 130, 7848-7850.

10. Colombo, V.; Galli, S.; Choi, H.J.; Han, G.D.; Maspero, A.; Palmisano, G.; Masciocchi, N.; Long, J.R. High thermal and chemical stability in pyrazole-bridged metal-organic frameworks with exposed metal sites. Chem. Sci. 2011, 2, 1311-1319.

11. Zheng, Q.; Yang, F.; Deng, M.; Ling, Y.; Liu, X.; Chen, Z.; Wang, Y.; Weng, L.; Zhou, Y. A porous metal-organic framework constructed from carboxylate-pyrazolate shared heptanuclear zinc clusters: Synthesis, gas adsorption, and guest-dependent luminescent properties. Inorg. Chem. 2013, 52, 10368-10374.

12. He, C.-T.; Tian, J.-Y.; Liu, S.-Y.; Ouyang, G.; Zhang, J.-P.; Chen, X.-M. A porous coordination framework for highly sensitive and selective solid-phase microextraction of non-polar volatile organic compounds. Chem. Sci. 2013, 4, 351-356. 
13. Ward, M.D. Polynuclear coordination cages. Chem. Commun. 2009, 30, 4487-4499.

14. Ayme, J.-F.; Beves, J.E.; Leigh, D.A.; McBurney, R.T.; Rissanen, K.; Schultz, D. A synthetic molecular pentafoil knot. Nat. Chem. 2012, 4, 15-20.

15. Hawes, C.S.; Kruger, P.E. Discrete and polymeric $\mathrm{Cu}(\mathrm{II})$ coordination complexes with a flexible bis-(pyridylpyrazole) ligand: Structural diversity and unexpected solvothermal reactivity. Aust. J. Chem. 2012, 66, 401-408.

16. Hawes, C.S.; Kruger, P.E. Synthesis and characterization of dinuclear $\mathrm{Co}(\mathrm{II}), \mathrm{Ni}(\mathrm{II})$ and $\mathrm{Cu}(\mathrm{II})$ unsaturated helical complexes from a novel dipyridyl-bispyrazole ligand. Polyhedron 2013, 52, $255-260$.

17. Glasson, C.R.K.; Meehan, G.V.; Clegg, J.K.; Lindoy, L.F.; Smith, J.A.; Keene, F.R.; Motti, C. Microwave synthesis of a rare $\left[\mathrm{Ru}_{2} \mathrm{~L}_{3}\right]^{4+}$ triple helicate and its interaction with DNA. Chem. Eur. J. 2008, 14, 10535-10538.

18. Vandevyver, C.D.B.; Chauvin, A.-S.; Comby, S.; Bünzli, J.-C.G. Luminescent lanthanide bimetallic triple-stranded helicates as potential cellular imaging probes. Chem. Commun. 2007, 17, 1716-1718.

19. Ferguson, A.; Squire, M.A.; Siretanu, D.; Mitcov, D.; Mathionière, C.; Clérac, R.; Kruger, P.E. A face-capped $\left[\mathrm{Fe}_{4} \mathrm{~L}_{4}\right]^{8+}$ spin crossover tetrahedral cage. Chem. Commun. 2013, 49, 1597-1599.

20. Lun, D.J.; Waterhouse, G.I.; Telfer, S.G. A general thermolabile protecting group strategy for organocatalytic metal-organic frameworks. J. Am. Chem. Soc. 2011, 133, 5806-5809.

21. Vaidhyanathan, R.; Iremonger, S.S.; Dawson, K.W.; Shimizu, G.K.H. An amine-functionalised metal organic framework for preferential $\mathrm{CO}_{2}$ adsorption at low pressures. Chem. Commun. 2009, 5230-5232.

22. Zhang, J.-P.; Kitagawa, S. Supramolecular isomerism, framework flexibility, unsaturated metal center, and porous property of $\mathrm{Ag}(\mathrm{I}) / \mathrm{Cu}(\mathrm{I}) 3,3^{\prime}, 5,5^{\prime}$-tetramethyl-4,4'- bipyrazolate. J. Am. Chem. Soc. 2008 , 130, 907-917.

23. Goswami, A.; Bala, S.; Pachfule, P.; Mondal, R. Comprehensive study on mutual interplay of multiple $\mathrm{V}$-shaped ligands on the helical nature of a series of coordination polymers and their properties. Cryst. Growth Des. 2013, 13, 5487-5498.

24. Bloch, W.M.; Babarao, R.; Hill, M.R.; Doonan, C.J.; Sumby, C.J. Post-synthetic structural processing in a metal-organic framework as a mechanism for exceptional $\mathrm{CO}_{2} / \mathrm{N}_{2}$ selectivity. J. Am. Chem. Soc. 2013, 135, 10441-10448.

25. King, P.; Clérac, R.; Anson, C.E.; Powell, A.L. The building block approach to extended solids: 3,5-pyrazoledicarboxylate coordination compounds of increasing dimensionality. Dalton Trans. 2004, 6, 852-861.

26. Ishikawa, R.; Nakano, M.; Fuyuhiro, A.; Takeuchi, T.; Kimura, S.; Kashiwagi, T.; Hagiwara, M.; Kindo, K.; Kaizaki, S.; Kawata, S. Construction of a novel topological frustrated system: A frustrated metal cluster in a helical space. Chem. Eur. J. 2010, 16, 11139-11144.

27. Miura, K.; Nishikimi, Y. (Takeda Pharmaceutical). Pyrroloquinoline Derivative and Use Thereof. International Patent WO2008153027A1, 18 December 2008.

28. Sheldrick, G.M. A short history of SHELX. Acta Crystallogr. Sect. A 2008, 64, 112-122. 
29. Sheldrick, G.M. SHELXL-97, Programs for X-Ray Crystal Structure Refinement; University of Göttingen: Göttingen, Germany, 2007.

30. Dolomanov, O.V.; Bourhis, L.J.; Gildea, R.J.; Howard, J.A.K.; Puschmann, H. OLEX2: A complete structure solution, refinement and analysis program. J. Appl. Cryst. 2009, 42, 229-341.

(C) 2014 by the authors; licensee MDPI, Basel, Switzerland. This article is an open access article distributed under the terms and conditions of the Creative Commons Attribution license (http://creativecommons.org/licenses/by/3.0/). 